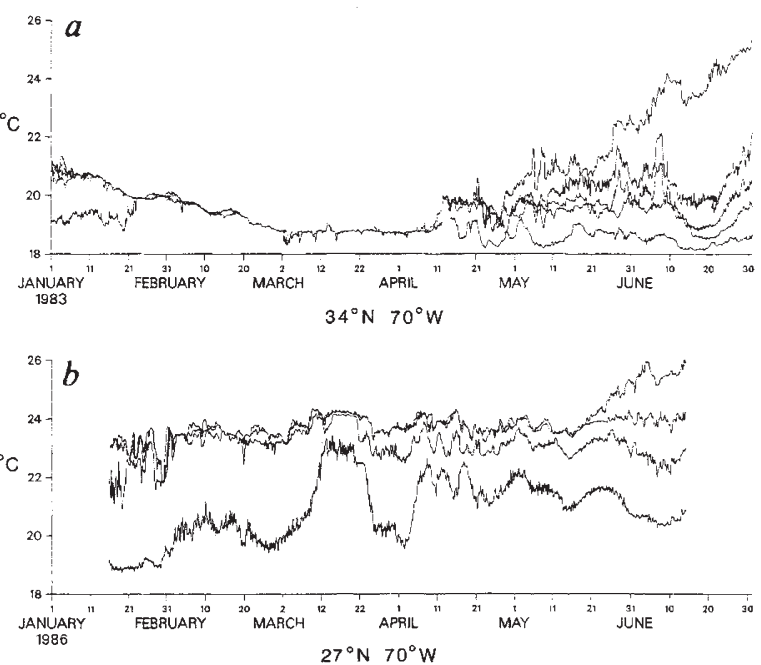

Time series of temperature at various depths in the upper ocean from two locations at the same longitude in the western North Atlantic. The times series (a) collected at $34^{\circ} \mathrm{N}, 70^{\circ} \mathrm{W}$ are from within the Sargasso Sea, while those collected at $27^{\circ}$ $\mathrm{N}, 70^{\circ} \mathrm{W}(b)$ are from the frontal region surveyed by Pollard and Regier. Data in a come from 5,50,75, 100, 150 and 200-m depths; note that the upper $200 \mathrm{~m}$ is essentially isothermal from late January to mid-April when it warms and stratifies rapidly. In contrast, $b$, which has data from 10, 40, 80,120 and 160-m depths, shows an upper ocean where the passage of ocean fronts (such as on about 12 March and again on 22 March) contributed abrupt changes in temperature and where a deep isothermal mixed layer did not form in the winter.

tions alone. On the other hand, if the mixed layer is deep and the vertical circulation active, plankton can be carried below the depth to which light penetrates and their population become limited by light levels. Because the spatial scales of the atmospheric forcing fields (wind, air temperature, relative humidity and radiation) that drive the seasonal cycle in the upper ocean are large, characteristically little less than $1,000 \mathrm{~km}$, there is no reason to expect mesoscale and small-scale spatial variability away from fronts in the mixed-layer depth or in other fields (such as the phytoplankton population) dependent on vertical exchange across the base of the mixed layer. Indeed, the planktonic spring blooms yield evidence of large spatial scales linked to those scales of the atmospheric forcing, a general poleward migration of the near-surface maximum in chlorophyll- $a$ concentration coupled to the northward progression of the restratification of the upper ocean in spring ${ }^{+}$.

Yet, in some parts of the ocean, there is considerable variability in chlorophyll content on $10-100 \mathrm{~km}$ scales'. A link between productivity and mesoscale and small-scale physical processes that carry nutrient-rich water up into the mixed layer have been proposed as an explanation ${ }^{\circ}$. If such an explanation is to be plausible, the physical processes should be apparent in detailed studies, such as Pollard and Regier's, of ocean regions characterized by energetic mesoscale and smaller scale variability. This is the case. The frontal region the authors surveyed had eddies embedded in the flow field associated with the front. The front itself was characterized by light (warm) water to the south and heavy (cold) water to the north. Constant density-surfaces sloped upwards from beneath the warm side, pinched together, and reached the ocean's surface with an almost vertical inclination at the front.

Pollard and Regier explain that large, $50-\mathrm{km}$ eddies distorted the frontal flow field, giving rise to smaller eddies, both cyclonic and anticyclonic, which were advected horizontally. As the small eddies moved through changes in stratification and horizontal shears, they conserved the physical quantity termed potential vorticity (the product of the rate of rotation or total vorticity of the water per unit height, times the vertical gradient of its density). This conservation was accomplished by changes in thickness so that, depending on the sign of change in the fluid's vorticity, the strata were either shrunk or stretched. Shrinking in height would bring water up from below, while stretching to conserve potential vorticity would push near-surface fluid to greater depth. Pollard and Regier calculate that the vertical velocities at the base of the small eddies could be as high as $50 \mathrm{~m} \mathrm{~d}^{-1}$.

In the area studied by Pollard and Regier, ocean fronts are common. Satellite images showed a number of fronts in the region at any one time, and at one location within the frontal region their occurrence dominated records of nearsurface temperature ( $b$ in the figure). Further, Pollard and Regier conclude that the eddies, which individually persisted for at least several days, were characteristic features of the fronts. Thus, one conclusion to be drawn from their study is that ocean frontal regions are sites of persistent, active vertical exchange on small horizontal scales (around $10 \mathrm{~km}$ ) between the near-surface and the upper thermocline regions of the ocean.

Robert A. Weller is in the Physical Oceanography Department, Woods Hole Oceanographic Institution, Woods Hole, Massachusetts 02543, USA.

1. Voorhis, A.D. J. geophys. Res. 16, 3809-3814 (1969).

2. Pollard, R.T. Nature 323, 433-435 (1986).

3. Pollard, R.T. \& Regier, Nature 348, 227-229(1990)

4. Strass, V. \& Woods, J.D. in Toward a Theory on BiologicalPhysical Interactions in the World Ocean (ed. Rothschild. B.J.) 113-136 (Kluwer, Drodrecht, 1988)

5. Gower, J.F.R., Denman, K.L. \& Holyer, R.J. Nature 288, $157-159(1980)$

6. Woods, $J$. in Toward a Theory on Biological-Physical Interactions in the World Ocean (ed. Rothschild, B.J.) 7-38 (Kluwer, Drodrecht, 1988).

\section{Sticking in orbit}

SPACE is gradually filling up with junk. The final stage rocket of every satellite is junk immediately; the satellite itself will be junk in due course; rockets that explode and spacecraft that break up spray further enormous numbers of tiny objects into orbit. At orbital velocity, impact with even a tiny piece of this space junk can wreck a satellite. Every new launch increases the danger.

This mass of fragments all in separate orbits, says Daedalus, is rather like the primitive solar system. Why did that ancient distribution of small particles clump together into the big planets we know today, instead of fragmenting further by repeated collisions? Solar system theorists reckon that the primordial planet stuff was sticky. Repeated impacts would then have glued it into a few sticky protoplanets big enough to sweep up and capture the remaining dust and gas.

So DREADCO's paint department is formulating a sticky paint for spacecraft. It will simply swallow up any tiny fragment that hits it, and flow over the scar to reestablish a smooth sticky surface. Even if the heat of impact degrades the paint in the immediate vicinity, the resulting charred volume will still be retained by the surrounding paint. If splashed by major impact, the paint is designed to extend like saliva into tenacious strings, which will ultimately contract under surface tension and return to the satellite.

New satellites can simply be painted with the novel coating before launch. Existing satellites and fragments pose a trickier problem. Daedalus recalls his previous scheme for vast space 'soap bubbles', made from a liquid loaded with high-polymer ring molecules of large radius. Such a bubble cannot be punctured. Any small hole is bound to be surrounded by at least one ring-molecule, whose random brownian wriggling soon seals the hole again. A few kilometre-sized sticky space bubbles, says Daedalus, would soon spread their adhesive around. They would simply absorb the very smallest particles, or slow them as they passed through the bubble walls and the gas between, dropping them from orbit. But larger chunks and complete satellites that hit a bubble would be comprehensively coated with adhesive by the impact. Even if they broke the bubble up, glue would be usefully spread round its orbit, ready to stick to further space junk.

The original processes of planet formation will thus be instructively replicated in earth orbit. All the space junk will gradually clump together. Ultimately a few large, messy satellites will result, each one a crazy glued-together agglomeration of space fragments large and small, easily tracked and avoided. The peril will be over!

David Jones 